\title{
Factors Associated with Prolonged Poor Glycemic Control in Type 2 Diabetes Mellitus (T2DM) Patients Followed in the Department of Internal Medicine at the Yalgado Ouedraogo Teaching Hospital, Ouagadougou (Burkina Faso)
}

\author{
Solo Traoré1 ${ }^{*}$, Oumar Guira1,2, Lassané Zoungrana1,2, Yempabou Sagna3 ${ }^{3}$, Réné Bognounou², \\ Constant B. Paré1, Désiré L. Dabourou ${ }^{4}$, Lassina Séré5, Daniel Zemba', Laurette S. Dembélé1, \\ Patricia D. Somé1, Patrice P. C. Savadogo1, Aline Tondé2, Tiéno Hervé1,6, Joseph Y. Drabo ${ }^{1,2}$ \\ ${ }^{1}$ Training and Research Unit in Health Sciences, Joseph Ki ZERBO University, Ouagadougou, Burkina Faso \\ ${ }^{2}$ Department of Internal Medicine, Yalgado Ouedraogo Teaching Hospital, Ouagadougou, Burkina Faso \\ ${ }^{3}$ Higher Institute of Health Sciences/Nazi Boni University, Bobo Dioulasso, Burkina Faso \\ ${ }^{4}$ Institute for Research in Health Sciences/National Center for Scientific and Technical Research, Ouagadougou, Burkina Faso \\ ${ }^{5}$ Department of Internal Medicine, Tengandogo Teaching Hospital, Ouagadougou, Burkina Faso \\ ${ }^{6}$ Department of Internal Medicine, Bogodogo Teaching Hospital, Ouagadougou, Burkina Faso \\ Email: ${ }^{\star}$ fredotraore@yahoo.fr
}

How to cite this paper: Traoré, S., Guira, O., Zoungrana, L., Sagna, Y., Bognounou, R., Paré, C.B., Dabourou, D.L., Séré, L., Zemba, D., Dembélé, L.S., Somé, P.D., Savadogo, P.P.C., Tondé, A., Hervé, T. and Drabo, J.Y. (2021) Factors Associated with Prolonged Poor Glycemic Control in Type 2 Diabetes Mellitus (T2DM) Patients Followed in the Department of Internal Medicine at the Yalgado Ouedraogo Teaching Hospital, Ouagadougou (Burkina Faso). Open Journal of Internal Medicine, 11, 1-26.

https://doi.org/10.4236/ojim.2021.111001

Received: January 21, 2021

Accepted: March 20, 2021

Published: March 23, 2021

\begin{abstract}
Background: Achieving and maintaining glycemic targets are a challenge for health practitioners around the world. We aimed to study the factors associated with prolonged poor diabetes control in the cohort of T2DM patients monitored and treated in the Department of Internal Medicine at the Yalgado OUEDRAOGO Teaching Hospital in Ouagadougou in order to optimize therapeutic education in these patients. Methodology. This was a descriptive and analytical cross-sectional study combining retrospective data collection from the last year of patient follow-up and prospective collection of some information. The study included all diabetic patients, aged at least 18 years old, followed and treated in the Department of Internal Medicine at the Yalgado OUEDRAOGO Teaching Hospital between January 1, 2010 and December 31, 2018 following a systematic random sampling with a sampling step of 10 . The variables collected were sociodemographic, anthropometric, lifestyle, cardiovascular risk factors and diabetes-related characteristics. To determine the risk factors associated with prolonged poor glycemic control, we per-
\end{abstract}


Copyright (C) 2021 by author(s) and Scientific Research Publishing Inc. This work is licensed under the Creative Commons Attribution International License (CC BY 4.0).

http://creativecommons.org/licenses/by/4.0/ formed modeling using logistic regression. All variables associated with prolonged poor glycemic control, in bivariate logistic regression with a p-value less than 0.20 were included in the full model. Later, we used a stepwise descending method to obtain the final model, which was then tested by a receiver operating characteristic (ROC) curve. The significance threshold was set at $5 \%$. Raw and fitted Odds-Ratio (OR) and 95\% confidence interval were presented. Results: 270 patients were included. Prolonged poor control of diabetes mellitus was observed in $73.70 \%$. The mean age was 55.97 years (SD: \pm 11.52 ) and the sex ratio was 0.6 in favor of female. The mean time since diabetes mellitus diagnoses was 5.85 years (SD: \pm 5.15$)$. A monthly gain of 92.62 USD (50.74\%) for average diabetes mellitus care expenditures of 55.82 USD (SD: 28.25) was reported. An overweight (55.92\%) and hypertension (41.85\%) were reported. Diabetes mellitus was complicated in $68.15 \%$. Patients were supported by their families in the management of their diabetes mellitus in $85.19 \%$. In multivariate analysis with bivariate logistic regression, low level of formal education ( $\mathrm{OR}=8.34,95 \% \mathrm{CI}[1.97-35.22] ; p<0.01)$, family support for diabetes mellitus management ( $\mathrm{OR}=0.65,95 \% \mathrm{CI}[0.45-0.94]$; $p=0.02)$, presence of abdominal obesity ( $\mathrm{OR}=2.27,95 \% \mathrm{CI}[1.08-4.77] ; p=0.03$ ), presence of a history of hospitalization (OR $=7.39,95 \%$ CI [2.97 - 18.39]; $p<$ $0.01)$, poor adherence to antidiabetic treatment $(\mathrm{OR}=2.97,95 \% \mathrm{CI}[1.42$ 6.18]; $p<0.01$ ), and the presence of microangiopathy ( $\mathrm{OR}=5.05,95 \% \mathrm{CI}$ [2.36 - 10.81]; $p<0.01$ ) were the factors independently associated with prolonged poor control of T2DM, with a ROC curve of 0.88 , which reflects a very good sensitivity and specificity of these factors. Conclusion: The imbalance of T2DM is multifactorial. Lifestyle, family environment, and compliance seem to be essential to ensure good glycemic control. Healthcare practitioners should take these elements into account in their daily patient assessment. A predictive score would be a tool to help identify patients at risk of diabetes imbalance and would contribute to improving their management.

\section{Keywords}

Type 2 Diabetes Mellitus, Prolonged Poor Control, Prevalence, Associated Factors, Burkina Faso

\section{Background}

The major interventional studies in diabetes mellitus unanimously recognize the benefit of glycemic control on the prevention of microvascular complications [1] [2] [3] [4]. Despite the controversies, this benefit also exists for macrovascular complications, but only becomes significant after a longer follow-up period, and gradually diminishes if glycemic control deteriorates [3].

Notwithstanding the variability of glycemic targets depending on patient characteristics, the recommended glycemic control for most patients with type 2 diabetes mellitus (T2DM) is defined by a hemoglobin A1c (HbA1c) target of 7\% or less (53 mmol/mol) [5] [6] [7]. Studies in African research centers reported 
poor glycemic control of T2DM patients in proportions ranging from $68.3 \%$ to 83.3\% [8]-[14]. These ranges were similar to those reported in Asia (81.6\%) [15] but higher than those reported in Europe [16] (37.4\%) and in the United States (38\%) [17].

The factors associated with poor glycemic control are demographic, anthropometric and behavioral factors, as well as factors related to diabetes mellitus and the environment [8] [9] [10] [11] [13] [14] [18]-[22].

In 2001, a descriptive and analytical cross-sectional study with retrospective data collection over a 4-year-period assessing glycemic control in Burkina Faso (BF) reported that $57.5 \%$ of diabetes mellitus patients had poor glycemic control. The factors influencing glycemic control found in that study were similar to those found in the literature [23]. Twenty years after this aforementioned study, we initiated the present work, which, compared to the first one, involved a population exclusively restricted to T2DM patients. Indeed, the authors agree to promote the analysis of data from populations with the same type of diabetes mellitus. Heterogeneity in the typology of diabetes mellitus would be a confounding factor. For them, each type of diabetes mellitus has its own specific characteristics due to epidemiology, environment, heredity, mode of onset, and progression [24] [25]. In addition, the criteria for defining poor glycemic control in the present effort is a methodological difference from the previous study.

The objective of this work was to determine the prevalence of prolonged poor glycemic control in T2DM and to identify factors associated with this observed prolonged condition in the cohort of T2DM patients monitored and treated in the Department of Internal Medicine of the Yalgado OUEDRAOGO Teaching Hospital in Ouagadougou in order to optimize therapeutic education of these patients.

\section{Methodology}

\subsection{Framework of the Study}

The study took place in the Department of Internal Medicine of the Yalgado OUEDRAOGO Teaching Hospital. The internal medicine department within the hospital is a multidisciplinary department that mainly deals with metabolic and endocrine pathologies and Human Immunodeficiency Virus (HIV) infection.

\subsection{Type and Population of the Study}

This was a descriptive and analytical cross-sectional study combining retrospective data collection from previous years on patients' follow-up and prospective data collection of missing information in their respective medical records. The study population consisted of a cohort of diabetes mellitus patients, at least 18 years of age, followed and treated in the Department of Internal Medicine of the Yalgado OUEDRAOGO Teaching Hospital between January 1, 2010 and December 31, 2018. 


\subsection{Criteria for Inclusion and Non-Inclusion}

Included in this study were T2DM patients followed and treated for at least one year with at least two $\mathrm{HbAlc}$ measurements within the last year of follow-up. Not included in the study were patients who had made a change in diabetes therapy within the last 3 months and also those who did not respond to the call to complete the missing information in the medical record.

\subsection{Sampling}

This was a systematic random sampling from all the patients who were followed in the internal medicine department between January 1, 2010 and December 31, 2018, following a draw step of 10 .

\subsection{Questionnaire}

The questionnaire was developed by the authors and their peers in the Department of Internal Medicine of the Yalgado OUEDRAOGO Teaching Hospital (Appendix 1). We also used Morisky's assessment questionnaire [26] in order to appreciate the quality of the treatment's compliance (Appendix 2).

\subsection{Operational Definitions}

Prolonged poor control of diabetes mellitus was reported in all patients with at least one of the outcomes of the various $\mathrm{HbAlc}$ measures in the last year of follow-up having a threshold above $7 \%$. Alternatively, fructosamine was used to assess poor glycemic control when at least one of the outcomes of the various fructosamine measurements in the last year of follow-up had a threshold above 290 micromoles/L. Adherence was measured using Morisky's questionnaire [26].

Lipid fraction abnormalities have been defined by adopting the 2017 standards of the French National Authority for Health on lipid assessment [27] (Appendix 3). Microangiopathy was defined by the presence of either neuropathy and/or nephropathy and/or retinopathy. Neuropathy was defined by an abnormality of the filament test and/or an abnormality of the tuning fork test and/or reflex abnormalities. Nephropathy was defined by measurement of 24 -hour proteinuria. The cut-off value for 24 -hour proteinuria was $300 \mathrm{mg} / 24 \mathrm{~h}$. Retinopathy was retained based on the results of fundus examinations with an ophthalmoscope. Macroangiopathy was defined by the presence of coronary artery disease, cerebrovascular disease and arteriopathy of the lower limbs. These findings were systematically searched for in the patients' follow-up medical records. Arteriopathy was defined both on clinical criteria (intermittent claudication, decubitus pain, absence of both foot pulses, gangrene, ischemic ulcer) and imaging criteria (systolic pressure index less than 0.9 , systolic pressure of the big toe greater than or equal to 1.3 accompanied by medicalcosis, calcifications, aneurysm and a perivascular environment appreciates hemodynamics for therapeutic purposes). The monthly gain consisted of the patient's total income plus donations. Monthly expenses (direct cost of management) for diabetes mellitus 
included expenses for: travel, consultation, testing, and purchase of medication and capillary blood glucose strips.

\subsection{Data Collection}

Data collection covered the period from February 15, 2020 to May 15, 2020. The collection tool was an anonymous questionnaire. Data collection was done in conjunction with follow-up consultations by a physician based on a survey form. The use of medical records made it possible to extract clinical data (the conditions leading to the identification of diabetes mellitus, time since diabetes mellitus diagnoses, presence of micro- or macro-angiopathy) and paraclinical data (blood glucose and $\mathrm{HbA1c}$ results) of previous years follow-up. The individual interview allowed the completion of certain missing information, in particular drug compliance based on items from Morisky's assessment questionnaire [26], certain sociodemographic and anthropometric characteristics and the financial status of the patients. Sociodemographic data (age, gender, level of education, average monthly income, marital status and residence), anthropometric data (weight, height, waist circumference and body mass index [weight divided by height squared]), and behavioral factors (alcohol and tobacco consumption) were collected.

\subsection{Ethical Considerations}

Confidentiality during the interview and respect for the anonymity of the questionnaire user were observed throughout this study. All personnel directly or indirectly involved in the data collection were health workers who were bound by strict professional secrecy. Free and informed verbal consent was obtained from patients prior to their inclusion in the study. Patients' refusal to participate in the study did not preclude their diabetes management and follow-up at the center. Personal information about each patient was coded with a number that did not identify the patient when the study results were published.

\subsection{Methods of Statistical Analysis}

Statistical analyses were performed using Statistical Product and Service Solutions (SPSS) version 20. Quantitative variables were presented as means or medians with indicators of dispersion (standard deviation and percentile). Qualitative variables were described by the frequencies of the different modalities.

To determine the risk factors associated with poor glycemic control, we used a logistic regression model. A bivariate analysis was performed to analyze the relationship between each variable and poor glycemic control. A final model was then determined by multivariate logistic regression. All variables associated with poor glycemic control in bivariate logistic regression with a $p$-value less than 0.20 were included in the full model. Then, we used a stepwise descending method to obtain the final model, which was then tested by a Receiver Operating Characteristic (ROC) curve. The significance level was set at 5\%. Raw and adjusted Odds-Ratio (OR) and 95\% confidence interval (CI) were presented. 


\section{Results}

\subsection{General Characteristics of the Study Population}

A total of 270 patients were included in this study. Poor glycemic control of diabetes mellitus was observed in $73.70 \%$ or approximately two-thirds of the patients in the cohort. The mean age of patients was 55.97 years (standard deviation [SD]: \pm 11.52 years) and the sex ratio (male/female) was 0.6 in favor of female. More than half of the population had a formal education (59.26\%). One out of two patients (55.92\%) was overweight. More than one out of two patients $(67.04 \%)$ had at least one underlying health condition recorded in their medical history. History of arterial hypertension was the most represented (41.85\%) condition. More than two thirds (85.19\%) of participants were supported by their families in the management of their diabetes mellitus. The average expenditure for diabetes mellitus care was 55.82 USD (SD: 28.25) per month. Table 1 shows the distribution of patients in the study according to their general characteristics.

\subsection{Characteristics of Diabetes Mellitus}

The average time period since diagnostic of diabetes mellitus was 5.85 years (SD: \pm 5.15 years). At least one complication of diabetes mellitus was found in more than half $(68.15 \%)$ of the population. Almost all $(94.81 \%)$ the patients in the study were receiving a pharmacological treatment for T2DM. The mean number of tablets taken was 2.94 (SD: \pm 1.56 ) per patient. Table 2 shows the distribution of study patients by their clinical status of diabetes mellitus.

\subsection{Factors Associated with Prolonged Poor Type 2 Diabetes Mellitus Control Univariate Analysis}

\subsubsection{Relationship between General Characteristics of the Study Population and Prolonged Poor Diabetes Mellitus Control}

The level of education $(p=0.02)$ and the presence of abdominal obesity ( $p=$ $0.04)$ were associated with prolonged poor diabetes mellitus control. Patients with low formal education had prolonged poor control of their diabetes mellitus. The same was true for those with abdominal obesity. There were no factors studied that were associated with prolonged poor diabetes mellitus control with respect to gender, age, medical history, lifestyle (tobacco, alcohol, physical activity), family status, place of residence and income level. In terms of family support, this variable was also associated with prolonged poor diabetes mellitus control $(p=0.03)$. The increase in monthly expenditures on diabetes mellitus care was correlated with prolonged poor diabetes mellitus control $(p<0.01)$. Expenditures on diabetes mellitus care were higher in patients with prolonged poor glycemic control.

\subsubsection{Relationship between Diabetes Mellitus and Prolonged Poor Control}

Dietary intake measures alone $(p<0.01)$, insulin use alone $(p<0.01)$ or in combination with an oral antidiabetic drugs $(p<0.01)$, combination of oral 
Table 1. Distribution of study patients by general characteristics $(\mathrm{N}=270)$.

\begin{tabular}{|c|c|c|}
\hline & Total (n) & Percentage (\%) \\
\hline \multicolumn{3}{|l|}{ Gender } \\
\hline Male & 105 & 38.89 \\
\hline Female & 165 & 61.11 \\
\hline \multicolumn{3}{|l|}{ Age (years) } \\
\hline$<65$ & 205 & 75.93 \\
\hline$\geq 65$ & 65 & 24.07 \\
\hline \multicolumn{3}{|l|}{ Education status } \\
\hline No formal education & 110 & 40.74 \\
\hline Primary & 80 & 29.63 \\
\hline Secondary & 60 & 22.22 \\
\hline Tertiary & 20 & 7.41 \\
\hline \multicolumn{3}{|l|}{ Body Mass Index } \\
\hline Underweight & 3 & 1.12 \\
\hline Normal weight & 116 & 42.96 \\
\hline Overweight & 88 & 32.59 \\
\hline Obesity & 63 & 23.33 \\
\hline \multicolumn{3}{|l|}{ Abdominal obesity } \\
\hline Yes & 171 & 63.33 \\
\hline No & 99 & 36.67 \\
\hline \multicolumn{3}{|l|}{ Medical history } \\
\hline Arterial hypertension & 113 & 41.85 \\
\hline HIV infection & 12 & 4.44 \\
\hline Viral hepatitis & 8 & 2.97 \\
\hline Pulmonary tuberculosis & 8 & 2.97 \\
\hline Stroke & 9 & 3.33 \\
\hline Kidney failure & 17 & 6.30 \\
\hline Solid cancers & 5 & 1.85 \\
\hline Osteoarthritis & 7 & 2.59 \\
\hline Depression & 2 & 0.74 \\
\hline \multicolumn{3}{|l|}{ Lifestyle } \\
\hline \multicolumn{3}{|l|}{ Alcohol consumption } \\
\hline Yes & 94 & 34.81 \\
\hline No & 176 & 65.19 \\
\hline \multicolumn{3}{|l|}{ Tobacco consumption } \\
\hline Yes & 26 & 9.63 \\
\hline No & 244 & 90.37 \\
\hline
\end{tabular}




\section{Continued}

Physical activity (exercise)

$\begin{array}{lll}\text { Yes } & 156 & 57.78 \\ \text { No } & 114 & 42.22\end{array}$

Family status

Lives surrounded (by family)

221

81.85

Lives alone

Place of residence

Hospital area

211

78.44

Outside hospital area

Income level per month (USD)

$<92.62$

50.74

[92.62 - 277.86[

137

30.74

[277.86 - 463.1[

83

14.81

$>463.1$

3.70

Family support in diabetes mellitus management

$\begin{array}{ccc}\text { Never } & 40 & 14.81 \\ \text { Little } & 40 & 14.81 \\ \text { Often } & 74 & 27.42 \\ \text { Always } & 116 & 42.96\end{array}$

Monthly expenses for diabetes mellitus care (USD)

$\begin{array}{ccc}\leq 27.79 & 53 & 19.63 \\ {[27.79-55.57]} & 124 & 45.93 \\ >55.57 & 93 & 34.44\end{array}$

HIV: Human Immunodeficiency Virus; USD: United States Dollar.

Table 2. Distribution of study patients by diabetes mellitus characteristics $(\mathrm{N}=270)$.

Total (n) Percentage (\%)

Family history of diabetes mellitus

$\begin{array}{lll}\text { Yes } & 128 & 47.41 \\ \text { No } & 142 & 52.59\end{array}$

Conditions leading to the identification of T2DM

$\begin{array}{ccc}\text { Unexpectedly } & 102 & 37.78 \\ \text { T2DM symptoms } & 129 & 47.78 \\ \text { Complications } & 30 & 14.44\end{array}$

Time since diabetes mellitus diagnostic (years)

$\begin{array}{ccc}<5 & 147 & 54.44 \\ {[5-10[} & 68 & 25.19 \\ \geq 10 & 55 & 20.37\end{array}$




\section{Continued}

History of hospitalization for a diabetes mellitus-related event

Yes

No

Microangiopathy

Nephropathy

Retinopathy

Neuropathy

Macroangiopathy

Arteriopathy

Stroke

Coronary artery disease

Associated risk factors

$$
\begin{aligned}
& \text { Hypertension } \\
& \text { Dyslipidemia }
\end{aligned}
$$

Type of treatment

\section{Dietary intake measures only}

Monotherapy

Oral antidiabetic drugs alone

Insulin

Bitherapy

Association of oral antidiabetic drugs

Insulin + oral antidiabetic drugs

Quality of compliance according to Morisky

$$
\text { Good }
$$$$
\text { Bad }
$$

Presence of self glucometer

Yes

No

Self-monitoring of blood glucose

Yes

No

T2DM: Type 2 Diabetes Mellitus.

antidiabetic drugs $(p<0.01)$, and poor adherence to Morisky's scale diabetes mellitus medication $(p<0.01)$ were factors associated with prolonged diabetes mellitus imbalance. These patients had prolonged poor glycemic control except for those on dietary measures alone, who were at lower risk of prolonged imbalance $(\mathrm{OR}=0.08,95 \% \mathrm{CI}[0.02-0.30] ; p<0.01)$. 


\subsection{Multivariate Analysis}

In multivariate analysis with bivariate logistic regression, six factors were independently associated with prolonged poor diabetes mellitus control. These were no formal education ( $\mathrm{OR}=8.34,95 \% \mathrm{CI}[1.97-35.22]$; $p<0.01)$; family support for diabetes mellitus management $(\mathrm{OR}=0.65,95 \% \mathrm{CI}[0.45-0.94] ; p=0.02)$; presence of abdominal obesity ( $\mathrm{OR}=2.27,95 \% \mathrm{CI}$ [1.08 - 4.77]; $p=0.03$ ); a history of hospitalization $(\mathrm{OR}=7.39,95 \% \mathrm{CI}[2.97-18.39]$; $p<0.01)$; poor adherence to antidiabetic treatment $(\mathrm{OR}=2.97,95 \%$ CI $[1.42-6.18] ; p<0.01)$; presence of microangiopathy ( $\mathrm{OR}=5.05,95 \% \mathrm{CI}[2.36-10.81] ; p<0.01)$.

Table 3 and Table 4 show respectively the relationship between the general characteristics of the study population and prolonged poor diabetes mellitus control and the relationship between diabetes mellitus characteristics and prolonged poor control.

The model specification was verified using the Roc statistical method. Figure 1 shows sensitivity and specificity of factors associated with prolonged poor control of T2DM.

The area under the curve was 0.88 , which reflects a very good sensitivity and specificity of these factors associated with poor long-term control of T2DM.

\section{Discussion}

\subsection{Prevalence of Prolonged Poor Control of Diabetes Mellitus}

Approximately two-thirds (73.70\%) of the patients in our study had prolonged poor diabetes mellitus control. This proportion was similar to that reported by Kibirige in Uganda (73.5\%) [28] and Omar in Sudan (71.9\%) [29]. It was lower in the studies by Tapsoba in Burkina Faso (57.5\%) [23], Souliotis in Greece (57.1\%) [30] and Cai in China (31.5\%) [31]. In contrast to studies by Tekalegn in Ethiopia (80\%) [32], Hai in Pakistan (81.6\%) [15] and Rahman in Bangladesh (82\%) [33] which found a higher prevalence.

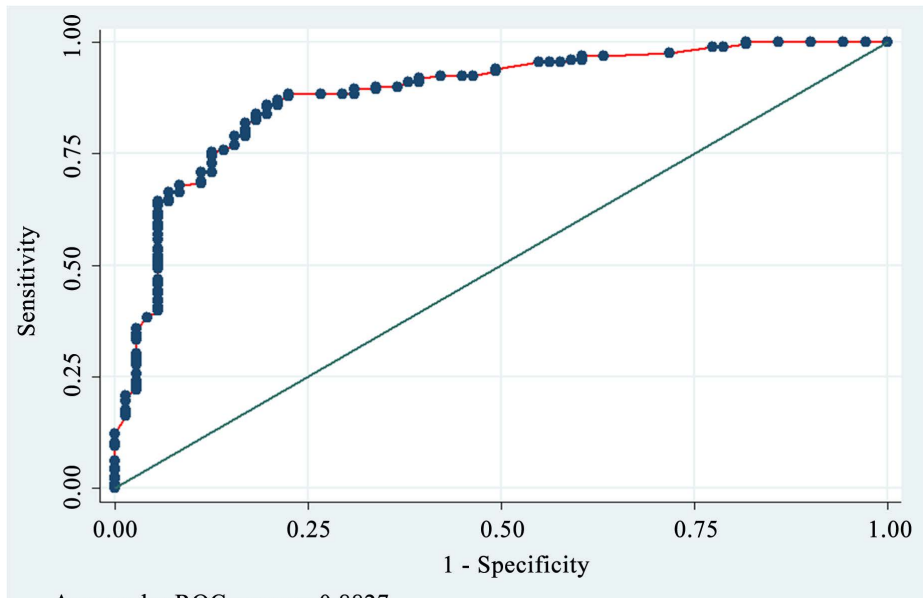

Area under $\mathrm{ROC}$ curve $=0.8827$

Figure 1. Sensitivity and specificity of factors associated with prolonged poor control of T2DM. 
Table 3. Relationship between general characteristics of the study population and prolonged poor diabetes mellitus control $(\mathrm{N}=$ 270).

\begin{tabular}{|c|c|c|c|c|c|c|c|c|}
\hline & \multicolumn{2}{|c|}{$\begin{array}{l}\text { Prolonged poor control } \\
\text { of diabetes mellitus }\end{array}$} & \multicolumn{3}{|c|}{ Univariate } & \multicolumn{3}{|c|}{ Multivariate } \\
\hline & Yes n (\%) & No $n(\%)$ & OR & $95 \% \mathrm{CI}$ & $p$ value & OR & $95 \% \mathrm{CI}$ & $p$ value \\
\hline \multicolumn{9}{|l|}{ Gender } \\
\hline Male & $81(77.14)$ & $24(22.86)$ & 1 & - & - & - & - & - \\
\hline Female & $118(71.52)$ & $47(28.48)$ & 0.74 & $0.42 ; 1.31$ & 0.30 & - & - & - \\
\hline \multicolumn{9}{|l|}{ Age (years) } \\
\hline$<65$ & $154(75.12)$ & $51(24088)$ & 1 & - & - & - & - & - \\
\hline$\geq 65$ & $45(69.23)$ & $20(30.77)$ & 0.74 & $0.40 ; 1.37$ & 0.34 & - & - & - \\
\hline Education status & & & & & 0.02 & - & - & 0.01 \\
\hline No formal education & 87 (79.09) & $23(20.91)$ & 4.62 & $1.71 ; 12.48$ & $<0.01$ & 8.34 & $1.97 ; 35.22$ & $<0.01$ \\
\hline Primary & $57(71.25)$ & $23(28.75)$ & 3.02 & $1.10 ; 8.27$ & 0.03 & 4.93 & $1.19 ; 20.32$ & 0.02 \\
\hline Secondary & $46(76.67)$ & $14(23.33)$ & 4.01 & $1.38 ; 11.64$ & 0.01 & 5.28 & $1.20 ; 23.10$ & 0.02 \\
\hline Tertiary & $9(45.00)$ & $11(55.00)$ & 1 & - & 1 & 1 & - & - \\
\hline Body Mass Index & & & & & 0.34 & & & - \\
\hline Underweight & $86(74.14)$ & $30(25.86)$ & 1 & - & - & - & - & - \\
\hline Normal weight & $3(100.00)$ & $0(0.00)$ & - & - & - & & & \\
\hline Overweight & $67(76.14)$ & $21(23.86)$ & 1.11 & $0.58 ; 2.11$ & 0.74 & - & - & - \\
\hline Obesity & $43(68.25)$ & $20(31.75)$ & 0.75 & $0.38 ; 1.47$ & 0.40 & - & - & - \\
\hline \multicolumn{9}{|l|}{ Abdominal obesity } \\
\hline Yes & $133(77.78)$ & $38(22.22)$ & 1.75 & $1.00 ; 3.84$ & 0.04 & 2.27 & $1.08 ; 4.77$ & 0.03 \\
\hline No & $66(66.67)$ & $33(33.33)$ & 1 & - & - & 1 & - & - \\
\hline \multicolumn{9}{|l|}{ Medical history } \\
\hline Yes & $136(75.14)$ & $45(24.86)$ & 1.24 & $0.70 ; 2.20$ & 0.44 & - & - & - \\
\hline No & $63(70.79)$ & $26(29.21)$ & 1 & - & - & - & - & - \\
\hline \multicolumn{9}{|l|}{ Type of Medical history } \\
\hline Arterial hypertension & $78(69.03)$ & $35(30.97)$ & 0.66 & $0.38 ; 1.14$ & 0.14 & - & - & - \\
\hline HIV infection & $11(91.67)$ & $1(8.33)$ & 4.09 & $0.51 ; 32.30$ & 0.18 & - & - & - \\
\hline Viral Hepatitis & $5(62.50)$ & $3(37.50)$ & 0.58 & $0.13 ; 2.50$ & 0.47 & - & - & - \\
\hline Pulmonary tuberculosis & $8(100.00)$ & $0(0.00)$ & 1 & - & - & - & - & - \\
\hline \multicolumn{9}{|l|}{ Alcohol consumption } \\
\hline Yes & $68(72.34)$ & $26(27.66)$ & 0.89 & $0.51 ; 1.58$ & 0.71 & - & - & - \\
\hline No & $131(74.43)$ & $45(25.57)$ & 1 & - & - & - & - & - \\
\hline \multicolumn{9}{|l|}{ Tobacco consumption } \\
\hline Yes & $22(84.62)$ & $4(15.38)$ & 2.08 & $0.69 ; 6.26$ & 0.19 & - & - & - \\
\hline No & $177(72.54)$ & $67(27.46)$ & 1 & - & - & - & - & - \\
\hline
\end{tabular}




\section{Continued}

Physical activity (exercise)

$\begin{array}{lccccc}\text { Yes } & 110(70.51) & 46(29.49) & 0.67 & 0.38 ; 1.17 & 0.16 \\ \text { No } & 89(78.07) & 25(21.93) & 1 & - & -\end{array}$

Family status

Lives surrounded (by family)

$\begin{array}{lllll}164(74.21) & 57(25.79) & 1.15 & 0.58 ; 2.29 & 0.69 \\ 35(71.43) & 14(28.57) & 1 & & \end{array}$

Lives alone

$35(71.43) \quad 14(28.57)$

\section{Place of residence}

Hospital area

Outside hospital area

$\begin{array}{ccccc}156(73.93) & 55(26.07) & 0.98 & 0.5 ; 1.92 & 0.97 \\ 43(72.88) & 16(27.12) & 1 & - & - \\ & & & & 0.31 \\ 101(73.72) & 36(26.28) & 1 & - & - \\ 67(80.72) & 16(19.28) & 1.49 & 0.77 ; 2.90 & 0.24 \\ 24(60.00) & 16(40.00) & 0.53 & 0.25 ; 1.11 & 0.10 \\ 7(70.00) & 3(30.00) & 0.83 & 0.20 ; 3.39 & 0.80\end{array}$

Family support in diabetes mellitus

management

Never
Little
Often
Always

$\begin{array}{cccccccc}34(85.00) & 6(15.00) & 1 & - & - & 1 & - & - \\ 32(80.00) & 8(20.00) & 0.70 & 0.22 ; 2.26 & 0.56 & 0.87 & 0.20 ; 3.74 & 0.86 \\ 53(71.62) & 21(28.38) & 0.44 & 0.16 ; 1.21 & 0.11 & 0.42 & 0.12 ; 1.49 & 0.18 \\ 80(68.97) & 36(31.03) & 0.39 & 0.15 ; 1.01 & 0.05 & 0.31 & 0.09 ; 1.04 & 0.05\end{array}$

Monthly expenses for diabetes mellitus care (USD)

0.01

$$
\leq 27.79
$$

[27.79 - 55.57]

Abbreviations: OR: odds ratio; CI: confidence interval; HIV: Human Immunodeficiency Virus; USD: United States Dollar.

Table 4. Relationship between characteristics of diabetes mellitus and prolonged poor control $(\mathrm{N}=270)$.

\begin{tabular}{|c|c|c|c|c|c|c|c|c|}
\hline & \multicolumn{2}{|c|}{$\begin{array}{l}\text { Prolonged poor control } \\
\text { of diabetes mellitus }\end{array}$} & \multicolumn{3}{|c|}{ Univariate } & \multicolumn{3}{|c|}{ Multivariate } \\
\hline & Yes n (\%) & No n (\%) & OR & $95 \% \mathrm{CI}$ & $p$ value & OR & $95 \% \mathrm{CI}$ & $p$ value \\
\hline \multicolumn{9}{|c|}{ Family history of diabetes mellitus } \\
\hline Yes & $95(74.22)$ & $33(25.78)$ & 1.05 & $0.61 ; 1.81$ & 0.85 & - & - & - \\
\hline No & $104(73.24)$ & $38(26.76)$ & 1 & - & - & & & \\
\hline $\begin{array}{c}\text { Conditions leading to the ide } \\
\text { of T2DM }\end{array}$ & & & & & 0.05 & & & - \\
\hline Fortuitous & $66(64.71)$ & $36(35.29)$ & 1 & - & - & - & - & - \\
\hline Functional signs & $104(80.62)$ & $25(19.38)$ & 2.26 & $1.24 ; 4.11$ & $<0.01$ & - & - & - \\
\hline Complications & $29(74.36)$ & $10(25.64)$ & 1.58 & $0.69 ; 3.61$ & 0.27 & - & - & - \\
\hline
\end{tabular}




\section{Continued}

Time since diabetes mellitus diagnoses (years)

$<5$
$[5-10[$
$\geq 10$

$\begin{array}{ccccc}108(73.47) & 39(26.53) & 1 & - & - \\ 50(73.53) & 18(26.47) & 1.00 & 0.52 ; 1.92 & 0.99 \\ 41(74.55) & 14(25.45) & 1.05 & 0.52 ; 2.15 & 0.88\end{array}$

History of hospitalization for a diabetes mellitus-related event

Yes

$123(94.62)$

7 (5.38)

$14.79 \quad 6.44 ; 33.96$

$<0.01$

7.39

$2.97 ; 18.39<0.01$

Microangiopathy

Yes

$76(54.29)$

$64(45.71)$

$140(90.32)$

$15(9.68)$

8.85

$4.64 ; 16.90$

$<0.01$

5.05

$2.36 ; 10.81$

$<0.01$

No

$59(51.30)$

$56(48.70)$

Macroangiopathy

Yes

$111(82.22)$

$24(17.78)$

2.47

No

$88(65.19)$

$47(34.81)$

\section{Associated risk factors}

Arterial hypertension

Yes

No

Dyslipidemia

Yes

No

\section{Type of treatment}

Dietary intake measures only

\section{Monotherapy}

Oral antidiabetic drugs alone

Insulin

\section{Bitherapy}

Association of oral antidiabetic drugs

Insulin + oral antidiabetic drugs

Quality of compliance according to Morisky

Good

Bad

$75(59.06)$

$124(86.71)$

4.52

$2.48 ; 8.23$

$<0.01$

2,97

$1.42 ; 6.18$

$<0.01$

Presence of self glucometer

Yes

No

$\begin{array}{cccc}108(72.48) & 48(27.52) & 0.86 & 0.50 ; 1.50 \\ 91(75.21) & 30(24.79) & 1 & -\end{array}$

Self-monitoring of blood glucose

$\begin{array}{lccccc}\text { Yes } & 92(73.02) & 34(26.98) & 0.93 & 0.54 ; 1.60 & 0.81 \\ \text { No } & 107(74.31) & 37(25.69) & 1 & - & -\end{array}$

Abbreviations: OR: odds ratio; CI: confidence interval; T2DM: type 2 diabetes mellitus. 
Several factors could explain these differences in proportion. For example, in Cai's study in China, where the prevalence of poor diabetes mellitus control was lower than in our patients, the assessment of diabetes mellitus control was done in patients at the beginning of their therapeutic education [31]. It has been documented that the profile of diabetes mellitus control tends to deteriorate overtime [8] [13] [15] [18] [33].

Similarly, in the Da Vico study, where the proportion of poor diabetes mellitus control was $36.7 \%$ at 12 months after the diagnostic of diabetes mellitus, all patients had received therapeutic education [34]. Our high proportion of poor diabetes mellitus control could be explained by the low completion rate of therapeutic education in the patient population, $24.3 \%$ [35] versus $100 \%$ [34]. Indeed, therapeutics education creates conditions for improved patient compliance and follow-up.

Compared to the study that was conducted in Burkina Faso [23], the endpoints for diabetes control differed: mean $\mathrm{HbAlc}$ versus normal $\mathrm{HbAlc}$ on a continuous basis. The greater difficulty in maintaining normal $\mathrm{HbAlc}$ on a continuous basis may explain why there were fewer patients in control than in the previous study in which HbAlc could vary over time.

\subsection{Factors Associated with Prolonged Poor Control of Diabetes}

\subsubsection{Sociodemographic Characteristics}

Gender was not associated with prolonged poor diabetes mellitus control in our study (OR $=0.74,95 \% \mathrm{CI}[0.42-1.31] ; p=0.30$ ), which were similar to findings by some authors [23] [36]. Others found different results: poor prolonged control associated with the female gender [8] [18] [19] [20] and poor prolonged control associated with the male gender [21] [33].

This result may raise questions. Indeed, since women attend health facilities more often than men [37], one would be tempted to think that they would have better results in terms of treatment effectiveness. However, a systematic review concluded that the reduction in HbAlc levels obtained during regular diabetes mellitus follow-up visits persisted for up to 6 months, and tended to diminish after 12 or 24 months [38].

Age was not a factor associated with prolonged poor diabetes mellitus control in our study ( $\mathrm{OR}=0.74,95 \% \mathrm{CI}[0.4-1.37] ; p=0.34)$. This result was similar to some studies [11] [22] [30] [39]. For other authors, age less than 40 years was associated with poor glycemic control [18] [21] [40] [41].

These results could be explained by methodological differences. Age being a continuous variable, to better appreciate the influence of age on poor diabetes mellitus control a better stratification was indicated than dichotomization into $<65$ years old and $\geq 65$ years old in our study.

Low educational level was associated with diabetes imbalance in our study, ( $\mathrm{OR}=8.34,95 \% \mathrm{CI}[1.97-35.22] ; p<0.01)$. Such an observation has also been reported by some authors [14] [19] [21] [42] [43] [44]. However, Demoz in a recent study found opposite results [18]. 
This negative influence of low formal education on glycemic control could be explained by the difficulty that health workers may have in conducting therapeutic education based on approaches or strategies adapted to the socio-cultural and educational level of our patients. It is therefore necessary to take this into account in the awareness and education directed at different sub-populations.

\subsubsection{Economic Characteristics}

Low income was not associated with prolonged poor diabetes mellitus control in our study $(\mathrm{OR}=0.83,95 \% \mathrm{CI}[0.20-3.39] ; p=0.80)$.

This result seems paradoxical, as access to care is more difficult for low-income people, especially in a context where there is no health insurance. Several studies of T2DM patients have shown that poor glycemic control is associated with low income [14] [19] [30] [33].

Our study showed that patients who had a high financial burden for diabetes mellitus care were more likely to have poor diabetes mellitus control $(\mathrm{OR}=2.55$, 95\% CI [1.21 - 5.39]; $p=0.01$ ).

This result could be explained by the financial burden of patients, which in the long run may have an impact on compliance and regularity of follow-up.

\subsubsection{Anthropometric Characteristics}

Patients with abdominal obesity had prolonged poor glycemic control in our study $(\mathrm{OR}=1.76,95 \% \mathrm{CI}[1.00-3.84] ; p=0.04)$. This observation has been made by several authors [10] [11] [18] [39].

Indeed, abdominal obesity is associated with insulin resistance. However, patients with insulin resistance are more difficult to treat because they require, for example, higher doses of insulin for insulin therapy.

\subsection{Lifestyle}

Smoking was not a factor associated with prolonged poor diabetes mellitus control in our study $(\mathrm{OR}=2.08,95 \% \mathrm{CI}[0.69-6.26] ; p=0.71)$. Some studies found contrary results [19] [43] [45] [46]. According to Ohkuma, HbAlc levels increase proportionally with the daily amount and duration of tobacco exposure [47].

In our study, alcohol consumption was not a factor associated with prolonged poor diabetes mellitus control ( $\mathrm{OR}=0.89,95 \% \mathrm{CI}$ [0.51 - 1.58]; $p=0.71$ ). Achila found opposite results [10]. Wiss in his study reported that alcohol reduced the HbA1c level, which may indicate a beneficial effect on glycemic control [48]. This study concluded that moderate and/or heavy alcohol consumption led to a significant reduction in the $\mathrm{HbAlc}$ level, highlighting the correlation between the amount of alcohol and the HbAlc level [31].

\subsection{Adherence to Treatment}

In our study, poor medication adherence was associated with prolonged poor diabetes mellitus control (OR $=2.97,95 \%$ CI $[1.42-6.18]$; $p<0.01)$. This obser- 
vation was found in many other studies [18] [33].

A study conducted in Burkina Faso reported that the main reasons for non-compliance with diabetes mellitus medication treatment were oversight and the geographical and financial inaccessibility of patients [49]. To these, we can add:

- Frequent interruptions in therapy due to denial of the chronicity of the illness,

- Work overload leading to a communication problem and having a negative impact on the doctor-patient relationship and trust. One meta-analysis found that physician consultation time in developing countries was less than $5 \mathrm{mi}-$ nutes in 18 of the 67 countries included in the study [50]. The patient's needs and concerns cannot be addressed in this amount of consultation time.

Physical activity practice was not a factor associated with prolonged poor diabetes mellitus control in our study ( $\mathrm{OR}=0.67,95 \%$ CI [0.38 - 1.17]; $p=0.16$ ). Studies have found similar results [16] [18]. Others, however, found contrary results [33] [39] [43] [51].

This result seems unexpected. Indeed, several meta-analyses and systematic reviews have clearly demonstrated the benefits of physical activity practice in terms of glycemic control.

In our study, neither the possession of a glucometer (OR $=0.86$, IC 95\% [0.5 $1.5] ; p=0.61)$, nor the practice of self-monitoring of blood glucose $(\mathrm{OR}=0.93$, 95\% CI [0.54 - 1.60]; $p=0.81$ ) were factors associated with diabetes mellitus imbalance. These data were contrary to those in the literature [19] [33].

Our result could be explained by the lack of optimization of the self-monitoring of blood glucose device (difficult access to strips, inefficient use, less reactivity or inability of our patients to self-manage) in our context.

Patients who were supported by their families were protected from prolonged poor diabetes mellitus control in our study $(\mathrm{OR}=0.65,95 \% \mathrm{CI}$ [0.45 - 0.94]; $p=$ 0.02). Similar results have been reported by some authors [15] [19].

This support from the family would help the patient to have a less contemptuous view of the disease. The family could also be a source of motivation for the patient through a personalized and often negotiated self-monitoring of blood glucose.

\subsection{Clinical Aspects of Diabetes}

Time since diabetes mellitus diagnostic was not associated with prolonged poor diabetes mellitus control in our study ( $\mathrm{OR}=1.05,95 \%$ CI [0.52 - 2.15]; $p=0.88)$. Some authors found similar results [23] [30]. Other studies found opposite results [8] [13] [15] [19] [33] [40] [43] [50] [52].

From a pathophysiological perspective, one would expect poor control of diabetes mellitus due to the continuous decline in $\beta$ cell functioning characteristic of T2DM and the difficulty in balancing diabetes mellitus over time. However, data modeling of large intervention studies has not been able to hypothesize a threshold value for the age of diabetes mellitus [1] [2] [3] [4]. 
Patients with a hospitalization history for an acute diabetes mellitus-related event had a higher risk of prolonged poor diabetes control (OR $=14.79,95 \% \mathrm{CI}$ [6.44 - 33.96]; $p<0.01$ ). In fact, according to one study, these hospitalizations occurred in patients who were generally unobservant, with already complicated diabetes mellitus showing HbA1c levels greater than $10.61 \%$ vs. $9.07 \%$ respectively before and after hospitalization [53].

Microangiopathy $(\mathrm{OR}=8.85,95 \% \mathrm{CI}[4.64-16.90] ; p<0.01)$ or macroangiopathy $(\mathrm{OR}=2.47,95 \% \mathrm{CI}[1.40-4.34] ; p<0.01)$ were factors associated with prolonged poor diabetes mellitus control. Authors found similar results [1] [2] [3] [4]. Demoz, on the other hand, reported opposite results [18]. In the literature, poor control of diabetes mellitus is thought to be associated with the progression of the disease to complications. However, the association of microangiopathy with poor glycemic control in our study seems unexpected. Perhaps it was necessary to correlate fasting blood glucose measurements to better appreciate this association rather than normal $\mathrm{HbA} 1 \mathrm{c}$ on a continuous basis.

\subsection{Diabetes Mellitus Treatment}

The use of oral antidiabetic drugs alone was not associated with prolonged poor diabetes mellitus control in our study ( $\mathrm{OR}=0.93,95 \% \mathrm{CI}[0.5-1.71] ; p=0.82)$. Our results were contrary to those of a study from Algerian [13]. On the other hand, the use of combination oral antidiabetic drugs was associated with prolonged poor diabetes mellitus control (OR $=11.33$, 95\% CI [2.89 - 44.33]; $p<$ 0.01). Our results were similar to those of the Algerian study [13]. The explanation may stem from therapeutic inertia related to the patient and/or the practitioner. Indeed, in practice, many dual therapy patients remain unbalanced but are reluctant to prescribe insulin; oral triple therapy is an option that is very often inaccessible in our context.

It is important to note that the use of combination of oral antidiabetic drugs is associated with poorer compliance due to the number of tablets and the number of doses to be taken. This could lead to a move towards prescribing a single antidiabetic drug.

Insulin use alone $(\mathrm{OR}=24.29,95 \% \mathrm{CI}[5.54-106] ; p<0.01)$ or in combination with oral antidiabetic drugs $(\mathrm{OR}=14.66,95 \%$ CI $[2.43-88.48] ; p<0.01)$ was a factor associated with prolonged poor diabetes mellitus control in our study. These results were similar to those of other studies [13] [16] [19] [30].

This result could be explained by the insulin recovery, in a context of prolonged diabetes mellitus condition that is therefore difficult to balance. In addition to this would be the problem of adherence to insulin therapy, its cost and the difficulties of conservation (disruptions of the cold chain). It is also known that the balance of diabetes mellitus tends to deteriorate with the duration of follow-up [8] [13] [15] [18].

Patients on dietary intake measures alone were protected against prolonged poor diabetes mellitus control in our study $(\mathrm{OR}=0.08,95 \% \mathrm{CI}[0.02-0.3]$; $p<$ 0.01). Such an observation was made by Tapsoba in Burkina Faso [23]. On the 
other hand, our results were contrary to those of an Algerian study [13].

Our result can be explained by the following treatment approach: when a patient in his last year of follow-up is still on hygienic dietary measures alone, this diabetes mellitus condition is most often balanced and there would be no need to prescribe medication.

\section{Limitations and Constraints of the Study}

This study assessed prolonged poor glycemic control and developed a score associated with the likelihood of poor glycemic control in T2DM patients in their final year of follow-up in the internal medicine department. However, there were limitations and biases that needed to be considered in interpreting the results. These were related to:

- An overestimation bias due to the HbAlc target greater than or equal to 7 to retain the diabetes mellitus imbalance, which is usually only the minimum value for judging the diabetes mellitus imbalance. The retrospective nature of the study did not provide all the data to individualize the targets.

- A reporting bias related to the declarative nature of the answers given to the questionnaire, particularly in the area of assessing compliance with Morisky's drug treatment [26].

Despite these limitations and biases, the observed results are in agreement with many studies in the literature as discussed above.

\section{Conclusion}

About two-thirds of the study population had prolonged poor control of diabetes. Factors associated with prolonged poor glycemic control were the educational level, the nature of family support for the management of diabetes mellitus, hospitalization for a diabetes-related event, the presence of abdominal obesity, poor adherence to medication, and the presence of microangiopathy. Lifestyle, environment (family support), and adherence to treatment seem to be key to good glycemic control. The practitioner should take these elements into account in his or her daily practice. In the context of developing countries, and in the absence of health insurance, a predictive score would be a tool to help in the identification of patients at risk of diabetes imbalance and would contribute to improving management of these patients.

\section{Conflicts of Interest}

The authors declare no conflicts of interest regarding the publication of this paper.

\section{References}

[1] UK Prospective Diabetes Study (UKPDS) Group (1998) Intensive Blood-Glucose Control with Sulphonylureas or Insulin Compared with Conventional Treatment and Risk of Complications in Patients with Type 2 Diabetes (UKPDS 33). Lancet, 
352, 837-853. https://doi.org/10.1016/S0140-6736(98)07019-6

[2] The Advance Collaborative Group (2008) Intensive Blood Glucose Control and Vascular Outcomes in Patients with Type 2 Diabetes. New England Journal of Medicine, 358, 2560-2572. https://doi.org/10.1056/NEJMoa0802987

[3] Duckworth, W., Abraira, C., Moritz, T., Reda, D., Emanuele, N., Reaven, P.D., et al. (2009) Glucose Control and Vascular Complications in Veterans with Type 2 Diabetes. New England Journal of Medicine, 360, 129-139. https://doi.org/10.1056/NEJMoa0808431

[4] The Action to Control Cardiovascular Risk in Diabetes Study Group (2008) Effects of Intensive Glucose Lowering in Type 2 Diabetes. New England Journal of Medicine, 358, 2545-2459. https://doi.org/10.1056/NEJMoa0802743

[5] Buse, J.B., Wexler, D.J., Tsapas, A., Rossing, P., Mingrone, G., Mathieu, C., et al. (2020) 2019 Update to: Management of Hyperglycemia in Type 2 Diabetes, 2018. A Consensus Report by the American Diabetes Association (ADA) and the European Association for the Study of Diabetes (EASD). Diabetes Care, 43, 487-493. https://doi.org/10.2337/dci19-0066

[6] International Diabetes Federation (2019) IDF Diabetes Atlas 9th Edition 2019. https://www.diabetesatlas.org/en/

[7] Darmon, P., Bauduceau, B., Bordier, L., Charbonnel, B., Cosson, E., Detournay, B., et al. (2019) Prise de position de la Société Francophone du Diabète (SFD) sur la prise en charge médicamenteuse de l'hyperglycémie du patient diabétique de type 2-2019. Médecine des Maladies Métaboliques, 13, 711-732. https://doi.org/10.1016/S1957-2557(19)30215-9

[8] Aschner, P., Gagliardino, J.J., Ilkova, H., Lavalle, F., Ramachandran, A., Mbanya, J.C., et al. (2020) Persistent Poor Glycaemic Control in Individuals with Type 2 Diabetes in Developing Countries: 12 Years of Real-World Evidence of the International Diabetes Management Practices Study (IDMPS). Diabetologia, 63, 711-721. https://doi.org/10.1007/s00125-019-05078-3

[9] Gazzaz, Z.J., Iftikhar, R., Jameel, T., Baig, M. and Murad, M.A. (2020) Association of Dyslipidemia and Comorbidities with Risk Factors among Diabetic Patients: A Retrospective Analysis. Diabetes, Metabolic Syndrome and Obesity: Targets and Therapy, 13, 935-941. https://doi.org/10.2147/DMSO.S235546

[10] Achila, O.O., Ghebretinsae, M., Kidane, A., Simon, M., Makonen, S. and Rezene, Y. (2020) Factors Associated with Poor Glycemic and Lipid Levels in Ambulatory Diabetes Mellitus Type 2 Patients in Asmara, Eritrea: A Cross-Sectional Study. Journal of Diabetes Research, 2020, Article ID: 5901569. https://doi.org/10.1155/2020/5901569

[11] Anioke, I.C., Ezedigboh, A.N., Dozie-Nwakile, O.C., Chukwu, I.J. and Kalu, PN. (2019) Predictors of Poor Glycemic Control in Adult with Type 2 Diabetes in South-Eastern Nigeria. African Health Sciences, 19, 2819-2828. https://doi.org/10.4314/ahs.v19i4.3

[12] Camara, A., Baldé, N.M., Sobngwi-Tambekou, J., Kengne, A.P., Diallo, M.M., Tchatchoua, A.P.K., et al. (2015) Poor Glycemic Control in Type 2 Diabetes in the South of the Sahara: The Issue of Limited Access to an HbAlc Test. Diabetes Research and Clinical Practice, 108, 187-192.

https://doi.org/10.1016/j.diabres.2014.08.025

[13] Belhadj, M., Arbouche, Z., Brouri, M., Malek, R., Semrouni, M., Zekri, S., et al. (2019) BAROMÈTRE Algérie: Enquête nationale sur la prise en charge des personnes diabétiques. Médecine des Maladies Métaboliques, 13, 188-194. 
https://doi.org/10.1016/S1957-2557(19)30055-0

[14] Ben El Mostafa, S., Boutayeb, W., Zitouni, N. and Maamri, A. (2019) Facteurs associés au mauvais contrôle glycémique chez des diabétiques de type 2 au Nord-Est du Maroc: À propos de 80 cas. Annales des Sciences de la Santé, 22, 1-14.

[15] Hai, A.A., Iftikhar, S., Latif, S., Herekar, F. and Patel, M.J. (2019) Diabetes Self-Care Activities and Their Relation with Glycemic Control in Patients Presenting to The Indus Hospital, Karachi. Cureus, 11, e6297. https://doi.org/10.7759/cureus.6297

[16] De Pablos-Velasco, P., Parhofer, K.G., Bradley, C., Eschwège, E., Gönder-Frederick, L., Maheux, P., et al. (2014) Current Level of Glycaemic Control and Its Associated Factors in Patients with Type 2 Diabetes across Europe: Data from the PANORAMA Study. Clinical Endocrinology, 80, 47-56. https://doi.org/10.1111/cen.12119

[17] Umpierrez, G.E., Isaacs, S.D., Bazargan, N., You, X., Thaler, L.M. and Kitabchi, A.E. (2002) Hyperglycemia: An Independent Marker of In-Hospital Mortality in Patients with Undiagnosed Diabetes. Journal of Clinical Endocrinology \& Metabolism, 87, 978-982. https://doi.org/10.1210/jcem.87.3.8341

[18] Demoz, G.T., Gebremariam, A., Yifter, H., Alebachew, M., Niriayo, Y.L., Gebreslassie, G., et al. (2019) Predictors of Poor Glycemic Control among Patients with Type 2 Diabetes on Follow-Up Care at a Tertiary Healthcare Setting in Ethiopia. BMC Research Notes, 12, Article No. 207. https://doi.org/10.1186/s13104-019-4248-6

[19] Afroz, A., Ali, L., Karim, M.N., Alramadan, M.J., Alam, K., Magliano, D.J., et al. (2019) Glycaemic Control for People with Type 2 Diabetes Mellitus in Bangladesh-An Urgent Need for Optimization of Management Plan. Scientific Reports, 9, Article No. 10248. https://doi.org/10.1038/s41598-019-46766-9

[20] Duarte, F.G., da Silva Moreira, S., da Conceição C Almeida, M., de Souza Teles, C.A., Reingold, A.L. and Moreira Jr., E.D. (2019) Sex Differences and Correlates of Poor Glycaemic Control in Type 2 Diabetes: A Cross-Sectional Study in Brazil and Venezuela. BMJ Open, 9, e023401. https://doi.org/10.1136/bmjopen-2018-023401

[21] Khunti, K., Chen, H., Cid-Ruzafa, J., Fenici, P., Gomes, M.B., Hammar, N., et al. (2020) Glycaemic Control in Patients with Type 2 Diabetes Initiating Second-Line Therapy: Results from the Global DISCOVER Study Programme. Diabetes, Obesity and Metabolism, 22, 66-78. https://doi.org/10.1111/dom.13866

[22] Smalls, B.L., Ritchwood, T.D., Bishu, K.G. and Egede, L.E. (2020) Racial/Ethnic Differences in Glycemic Control in Older Adults with Type 2 Diabetes: United States 2003-2014. International Journal of Environmental Research and Public Health, 17, Article No. 950. https://doi.org/10.3390/ijerph17030950

[23] Tapsoba, M.T. (2001) Evaluation de l'équilibre glycémique à partir d'une étude rétrospective sur 04 ans chez les diabétiques suivis au CHNYO. Thèse de doctorat en médecine, No. 11, Université de Ouagadougou, Ouagadougou.

[24] Xie, F.Y., Chan, J.C.N. and Ma, R.C.W. (2018) Precision Medicine in Diabetes Prevention, Classification and Management. Journal of Diabetes Investigation, 9, 998-1015. https://doi.org/10.1111/jdi.12830

[25] Kalra, S., Das, A.K., Bajaj, S., Priya, G., Ghosh, S., Mehrotra, R.N., et al. (2020) Utility of Precision Medicine in the Management of Diabetes: Expert Opinion from an International Panel. Diabetes Therapy, 11, 411-422. https://doi.org/10.1007/s13300-019-00753-5

[26] Morisky, D.E., Ang, A., Krousel-Wood, M. and Ward, H.J. (2008) Predictive Validity of a Medication Adherence Measure in an Outpatient Setting. Journal of Clinical Hypertension, 10, 348-354.

https://doi.org/10.1111/j.1751-7176.2008.07572.x 
[27] Haute Autorité de Santé (2014) Principales dyslipidémies. Stratégies de prise en charge. Haute Autorité de Santé, Paris. https://www.has-sante.fr

[28] Kibirige, D., Atuhe, D., Sebunya, R. and Mwebaze, R. (2014) Suboptimal Glycaemic and Blood Pressure Control and Screening for Diabetic Complications in Adult Ambulatory Diabetic Patients in Uganda: A Retrospective Study from a Developing Country. Journal of Diabetes \& Metabolic Disorders, 13, Article No. 40. https://doi.org/10.1186/2251-6581-13-40

[29] Omar, S.M., Musa, I.R., Osman, O.E. and Adam, I. (2018) Assessment of Glycemic Control in Type 2 Diabetes in the Eastern Sudan. BMC Research Notes, 11, Article No. 373. https://doi.org/10.1186/s13104-018-3480-9

[30] Souliotis, K., Koutsovasilis, A., Vatheia, G., Golna, C., Nikolaidi, S., Hatziagelaki, E. et al. (2020) Profile and Factors Associated with Glycaemic Control of Patients with Type 2 Diabetes in Greece: Results from the Diabetes Registry. BMC Endocrine Disorders, 20, Article No. 16. https://doi.org/10.1186/s12902-020-0496-7

[31] Cai, X.L., Hu, D.Y., Pan, C.Y., Li, G.W., Lu, J.M., Ji, Q.H., et al. (2020) Evaluation of Effectiveness of Treatment Paradigm for Newly Diagnosed Type 2 Diabetes Patients in Chin: A Nationwide Prospective Cohort Study. Journal of Diabetes Investigation, 11, 151-161. https://doi.org/10.1111/jdi.13092

[32] Tekalegn, Y., Addissie, A., Kebede, T. and Ayele, W. (2018) Magnitude of Glycemic Control and Its Associated Factors among Patients with Type 2 Diabetes at Tikur Anbessa Specialized Hospital, Addis Ababa, Ethiopia. PloS ONE, 13, e0193442. https://doi.org/10.1371/journal.pone.0193442

[33] Rahman, M., Nakamura, K., Hasan, S.M.M., Seino, K. and Mostofa, G. (2020) Mediators of the Association between Low Socioeconomic Status and Poor Glycemic Control among Type 2 Diabetics in Bangladesh. Scientific Reports, 10, Article No. 6690. https://doi.org/10.1038/s41598-020-63253-8

[34] Da Vico, L., Monami, M., Biffi, B., Lamanna, C., Martelli, C., Marchionni, N., et al. (2013) Targeting Educational Therapy for Type 2 Diabetes: Identification of Predictors of Therapeutic Success. Acta Diabetologica, 50, 309-317. https://doi.org/10.1007/s00592-012-0377-2

[35] Guira, O., Ouedraogo, A., Zoungrana, L., Bognounou, R., Traore, S., Tonde, A. and Drabo, Y.J. (2019) Evaluation du suivi trimestriel des patients diabétiques en médecine interne au Centre Hospitalier Universitaire Yalgado Ouedraogo, Ouagadougou. Revue Africaine de Médecine Interne, 6, 21-26.

[36] Otieno, C., Kariuki, M. and Ng'ang'a, L. (2003) Quality of Glycaemic Control in Ambulatory Diabetics at the Out-Patient Clinic of Kenyatta National Hospital, Nairobi. East African Medical Journal, 80, 406-410.

https://doi.org/10.4314/eamj.v80i8.8731

[37] Institut National de la Statistique et de la Démographie (2016) Annuaire Statistique 2016. Institut National de la Statistique et de la Démographie, Burkina Faso.

https://www.sante.gov.bf

[38] Captieux, M., Pearce, G., Parke, H.L, Epiphaniou, E., Wild, S., Taylor, S.J.C., et al. (2018) Supported Self-Management for People with Type 2 Diabetes: A Meta-Review of Quantitative Systematic Reviews. BMJ Open, 8, e024262. https://doi.org/10.1136/bmjopen-2018-024262

[39] Wu, M., Wen, J.B., Qin, Y., Zhao, H.L., Pan, X.Q., Su, J., Du, W.C., Pan, E.C., Zhang, Q., Zhang, N., Sheng, H.Y., Liu, C.L. and Shen, C. (2017) Familial History of Diabetes is Associated with Poor Glycaemic Control in Type 2 Diabetics: A Cross-Sectional Study. Scientific Reports, 7, Article No. 1432. 
https://doi.org/10.1038/s41598-017-01527-4

[40] Cheng, L.J., Wang, W., Lim, S.T. and Wu, VX. (2019) Factors Associated with Glycaemic Control in Patients with Diabetes Mellitus: A Systematic Literature Review. Journal of Clinical Nursing, 28, 1433-1450. https://doi.org/10.1111/jocn.14795

[41] Shamshirgaran, S.M., Mamaghanian, A., Aliasgarzadeh, A., Aiminisani, N., Iranparvar-Alamdari, M. and Ataie, J. (2017) Age Differences in Diabetes-Related Complications and Glycemic Control. BMC Endocrine Disorders, 17, Article No. 25 https://doi.org/10.1186/s12902-017-0175-5

[42] Mirahmadizadeh, A., Khorshidsavar, H., Seif, M. and Sharifi, M.H. (2020) Adherence to Medication, Diet and Physical Activity and the Associated Factors Amongst Patients with Type 2 Diabetes. Diabetes Therapy, 11, 479-494. https://doi.org/10.1007/s13300-019-00750-8

[43] Fekadu, G., Bula, K., Bayisa, G., Turi, E., Tolossa, T. and Kebebe, H. (2019) Challenges and Factors Associated with Poor Glycemic Control among Type 2 Diabetes Mellitus Patients at Nekemte Referral Hospital, Western Ethiopia. Journal of Multidisciplinary Healthcare, 12, 963-974. https://doi.org/10.2147/JMDH.S232691

[44] Kazemian, P., Shebl, F.M., Mc Cann, N., Walensky, R.P. and Wexler, D.J. (2019) Evaluation of the Cascade of Diabetes Care in the United States, 2005-2016. JAMA Internal Medicine, 179, 1376-1385. https://doi.org/10.1001/jamainternmed.2019.2396

[45] Peng, K., Chen, G., Liu, C., Mu, Y., Ye, Z., Shi, L., et al. (2018) Association between Smoking and Glycemic Control in Diabetic Patients: Results from the Risk Evaluation of Cancers in Chinese Diabetic Individuals: A Longitudinal (REACTION) Study. Journal of Diabetes, 10, 408-418. https://doi.org/10.1111/1753-0407.12625

[46] Willi, C., Bodenmann, P., Ghali, W.A., Faris, P.D. and Cornuz, J. (2007) Active Smoking and the Risk of Type 2 Diabetes: A Systematic Review and Meta-Analysis. $J A M A, 298,2654-2664$. https://doi.org/10.1001/jama.298.22.2654

[47] Ohkuma, T., Iwase, M., Fujii, H., Kaizu, S., Ide, H., Jodai, T., et al. (2015) Dose- and Time-Dependent Association of Smoking and Its Cessation with Glycemic Control and Insulin Resistance in Male Patients with Type 2 Diabetes Mellitus: The Fukuoka Diabetes Registry. PLoS ONE, 10, e0122023.

https://doi.org/10.1371/journal.pone.0122023

[48] Wiss, D.A. (2019) The Relationship Between Alcohol and Glycohemoglobin: A Biopsychosocial Perspective. BioResearch Open Access, 8, 146-154. https://doi.org/10.1089/biores.2019.0009

[49] Tiéno, H., Bouda M., Ouédraogo, D-D., Traoré, R., Ouédraogo, C. and Drabo, Y.J. (2010) Observance du traitement antidiabétique dans un pays en développement: Le cas du Burkina Faso (Afrique subsaharienne). Médecine des Maladies Métaboliques, 4, 207-210. https://doi.org/10.1016/S1957-2557(10)70046-8

[50] Irving, G., Neves, A.L., Dambha-Miller, H., Oishi, A., Tagashira, H., Verho, A., et al. (2017) International Variations in Primary Care Physician Consultation Time: A Systematic Review of 67 Countries. BMJ Open, 7, e017902.

https://doi.org/10.1136/bmjopen-2017-017902

[51] Pokhrel, S., Shrestha, S., Timilsina, A., Sapkota, M., Bhatt, M.P. and Pardhe, B.D. (2019) Self-Care Adherence and Barriers to Good Glycaemic Control in Nepalese Type 2 Diabetes Mellitus Patients: A Hospital-Based Cross-Sectional Study. Journal of Multidisciplinary Healthcare, 12, 817-826. https://doi.org/10.2147/JMDH.S216842

[52] Alzaheb, R. and Altemani, A. (2018) The Prevalence and Determinants of Poor 
Glycemic Control among Adults with Type 2 Diabetes Mellitus in Saudi Arabia. Diabetes, Metabolic Syndrome and Obesity: Targets and Therapy, 11, 15-21. https://doi.org/10.2147/DMSO.S156214

[53] Mekni, S., Nacef, I.B., Jenouiz, Z., Rojbi, I., Mchirgui, N., Lakhoua, Y., et al. (2017) Impact of Hospitalization on Glycemic Control in Patients with Poorly Controlled Diabetes. Annales d' Endocrinologie, 78, 421-422.

https://doi.org/10.1016/j.ando.2017.07.668 


\section{Appendix 1: Data Collection Sheet}

File number: File number:

\section{1) GENERAL INFORMATION}

Surname and First Names (Initials):

Age in the last year of follow-up (in years):

Sex: Male /__ Female /__ /

Patient's area of residence (hospital's implantation area): Yes / _ / No /__

Level of education: Not Educated /__ Primary level /__ Secondary level /__

University level /__ /

Family status: $\square$ Lives as a couple (married, surrounded by family) $\square$ No (single, divorced, widowed, separated/divorced)

Average monthly income in USD:

$$
\square<92.62 \square[92.62 \text { - 277.86[ } \square[277.86 \text { - 463.1[ } \square>463.1
$$

How much do you estimate the different monthly expenses to care for your diabetes (in USD)?

$$
\leq 27.79 \square] 27.79 \text { - 55.57] } \square>55.57
$$

Do you feel that your family is an important help in the management of your diabetes?

$$
\text { /_/ never I_/ a little I_/ often I_/ always }
$$

\section{2) MEDICAL HISTORIES}

Lifestyle:

Alcohol: $\square$ Drinking Alcohol $\square \square$ No-drinking

NB: 3 glasses per day for men and 2 glasses per day for women:

Tobacco: $\square$ Current smoker (have smoked in the last 30 days)

\section{$\square$ Non-smoker $\square \square$ Former smoker}

If former smoker: $\square<3$ years $\square \square>3$ years

Do you practice sports (jogging, walking, indoors, ...)? $\square$ Yes $\square$ No

If yes, how many times a week?

$\square$ Less than 3 times $\quad \square \square$ More than 3 times

Are there diabetics in your family?

$\square$ Yes $\quad \square \square$ No
Medical ATCD:
$\square$ Arterial hypertension $\square \square$ HIV infection $\quad \square \square$ Viral hepatitis
$\square$ Pulmonary tuberculosis $\square \square$ Stroke Kidney failure $\quad \square \square$ Solid cancers
$\square$ Osteoarthritis $\quad \square \square$ Depression

\section{3) HISTORY OF DIABETES}

How long have you been aware of your diabetes (in years):

$\square<5$ $\square[5-10[$ $\geq 10$

Circumstance of Discovery of Diabetes: Incidental /__ Functional Signs /__ Complication /__ / Type of treatment during the last year of follow-up: MHD alone /__/; Insulin /__; $\mathrm{ADO} /$ _ / Have you ever been hospitalized: Yes / _ / No /__ 
Do you have a glucometer?: Yes /__ No / _ /

If yes, do you monitor your blood glucose at home at least once a month?

Yes / / No / /

\section{4) CLINICAL EXAMINATION}

a) Vitals during the last year of follow-up:

Weight (kg): Size $(m)$

Height $(\mathrm{cm})$

TAS (mmHg) TAD (mmHg)

b) Search for complications during the last year of follow-up

Nephropathy: yes /__ no /__ Retinopathy: yes /__ no /_ I

Glaucoma: yes /__ no /__ Cataract: yes /_/ no /_/

Neuropathy: yes /__ no /__ Arteriopathy: yes /__ no /_ /

Diabetic foot: yes /__ no /__ Stroke: yes /__ no /__

Coronary insufficiency (Angina, MDI, ...): yes /__ no /__

Dyslipidemia: yes /__ no /__ /

c) PARACLINIC

\begin{tabular}{lllll}
\hline & Q1 & Q2 & Q3 & Q4 \\
\hline HbA1c & & & & \\
Fructosamine & & & \\
\hline Q: Quarter.
\end{tabular}

Lipid fraction abnormalities ( $\mathrm{mmol} / \mathrm{l})$

Triglycerides: Total cholesterol. HDLc

LDLc................... MDRD (kidney function):

\section{Appendix 2: Morisky Compliance Assessment}

1 Do you sometimes forget to take your tablets?

Sometimes people don't take their medication for reasons other than

2 forgetting. Thinking about the last two weeks, were there days when you didn't take your medication?

3 Have you ever reduced the dose or stopped taking your medication? Without informing your doctor, because you felt less well while taking them.

4

When you travel or leave home, do you ever forget to take your medication with you?

5 Did you take your medication yesterday?

6 When you have fewer or more of your symptoms, do you ever stop taking your medication?

7 Having to take medication every day is a real inconvenience for some people. Do you sometimes get upset about having to adhere to your treatment?

Do you ever have trouble remembering to take all your medications?

8 Never rarely from time to time sometimes

Regularly all the time 
Interpretation: Each answer "no" is considered as " 1 " and each "yes" is classified as “0”.

The exception is made in question 5, where each "Yes" answer is considered as " 1 " and each "No" is classified as " 0 ".

For question 8 , if a patient chooses an answer "never/rarely" the score is " 1 " and if he chooses the answer "all the time" the score is " 0 ".

The answers "occasionally, sometimes, regularly" are respectively evaluated as “0.25, 0.5, 0.75”.

\begin{tabular}{ccc}
\hline Score & Observance \\
\hline$\geq 8$ & Good \\
{$[6-8[$} & Average \\
$<6$ & Wrong \\
\hline
\end{tabular}

\section{Appendix 3: Lipid Fraction Abnormalities Defined by 2017 Standards of the French National Authority for Health on Lipid Assessment}

Cholestérol total: $4.10-5.20 \mathrm{mmol} / \mathrm{l}$ ou $1.6-2.0 \mathrm{~g} / \mathrm{l}$

Triglycéride: 0.40 - $1.70 \mathrm{mmol} / \mathrm{l}$ ou 0.35 - $1.50 \mathrm{~g} / \mathrm{l}$

HDL-cholestérol: superior a $1.0 \mathrm{mmol} / \mathrm{l}$ ou suprior a $0.40 \mathrm{~g} / \mathrm{l}$

LDL-cholestérol: inferior a $4.1 \mathrm{mmol} / \mathrm{l}$ ou inferior a $1.60 \mathrm{~g} / \mathrm{l}$ 